\title{
ATAQUE DE CACHORRO: ESTADO DE NECESSIDADE OU LEGITIMA DEFESA?
}

\author{
Débora Aparecida Mafra Moras, Danielle Yurie Moura da Silva
}

Universidade do Oeste Paulista - UNOESTE, Curso de Direito, Presidente Prudente, SP. E-mail: deboraamoras@outlook.com.br

\section{RESUMO}

Trata o presente artigo científico de um estudo acerca dos institutos de estado de necessidade e legítima defesa, previsto no pátrio ordenamento jurídico, no Código Penal brasileiro, como causa excludente de ilicitude. E, neste sentido, o Estado que não tem condição de estar presente em todas as ocasiões garante à vítima o direito de evadir-se ou, até mesmo, de se defender da agressão. Contudo algumas situações podem caracterizar um conflito aparente de normas, dificultando o enquadramento do instituto correto no fato. Um desses casos é o ataque de cachorro, tornando o tema estado de necessidade e legítima defesa essencial. O método aplicado foi o dedutivo legal, baseado na interpretação da legislação, jurisprudências e doutrinas. Concluise que o ataque de um animal irracional pode ser caracterizado como estado de necessidade ou legítima defesa, o qual dependerá do reconhecimento da ação humana ou não, análise que deverá ser realizada no caso concreto.

Palavras - chave: Direito Penal- Estado de Necessidade- Legítima Defesa- Excludentes de Ilicitude.

\section{DOG ATTACK: STATE OF NECESSITY OR LEGITIMATE DEFENSE?}

\begin{abstract}
It treats the present scientific article of a study about the institutes of state of necessity and selfdefense, foreseen in the Brazilian legal system, in the Brazilian Penal Code, as an exclusionary cause of illegality. And, in this sense, the State that is not able to be present at all times guarantees the victim the right to evade or even defend himself from aggression. However, some situations may characterize an apparent conflict of norms, making it difficult to frame the correct institute in fact. One such case is the dog attack, making the subject a state of necessity and legitimate self- defense essential. The method applied was the legal deductive, based on the interpretation of the legislation, jurisprudence and doctrines. It is conclude that the attack of an irrational animal can be characterized as a state of necessity or self- defense, which will depend on the recognition of human action or not, an analysis that should be carried out in the concrete case. Keywords: Criminal Law- State of Need- Legitimate Defense- Exclusion of Unlawfulness.
\end{abstract}




\section{INTRODUÇÂO}

A excludente de ilicitude a ser utilizada, quando um indivíduo é atacado por um cão, é motivo de grande confusão entre a população. A falta de entendimento dos requisitos, para determinar se houve estado de necessidade ou legítima defesa, acarreta essa confusão. Sendo assim, o presente artigo tem, por objetivo, demonstrar em quais casos se utilizará cada uma dessas excludentes.

Inicialmente, cabe ressaltar-se que o instituto de estado de necessidade e legítima defesa está previsto nos artigos 23, 24 e 25 do Código Penal (BRASIL, 1940).

Assim, o objetivo deste trabalho é estudar os requisitos do estado de necessidade e de legítima defesa, os elementos históricos, as limitações, as teorias e suas modalidades, sempre analisando as semelhanças e diferenças em suas aplicabilidades.

\section{ESTADO DE NECESSIDADE}

O conceito de estado de necessidade pode ser encontrado no artigo 24 do Código Penal Brasileiro (BRASIL, 1940), o qual dispõe:

Art. 24: Considera-se em estado de necessidade quem pratica o fato, para salvar-se de perigo atual, que não provocou por sua vontade, nem podia, de outro modo, evitar, direito próprio ou alheio, cujo sacrifício, nas circunstâncias, não era razoável exigir-se.

No estado de necessidade, conforme expõe Capez (2015, p.293),

(...) Existem dois ou mais bens jurídicos postos em perigo, de modo que a preservação de um depende da destruição dos demais. Como o agente não criou a situação de ameaça pode escolher, dentro de um critério de razoabilidade ditado pelo senso comum, qual deve ser salvo.

Portanto, é a situação em que o agente atua, para salvar de perigo atual e inevitável um bem ou direito que não provocou voluntariamente.

Neste sentido, haverá uma colisão de bens tutelados, ou seja, o direito de cada um dos agentes, pois há a incidência de uma ameaça que pode ser causada por fato humano, fato animal ou, até mesmo, forças naturais. Contudo a reação, para salvaguardar direito seu ou alheio, só será considerada como estado de necessidade, se a atitude tomada for imprescindível para a sobrevivência desses agentes.

Desse modo, ainda que o agente inicie uma conduta prescrita em lei, definida como crime (Conduta Típica), não terá ele cometido um crime, desde que haja o preenchimento das disposições legais desse instituto.

O instituto estado de necessidade possui três teorias: a primeira delas é denominada de teoria unitária, que foi a adotada pelo Código Penal, entendendo que é, sempre, uma causa de exclusão da ilicitude e, portanto, não atua como causa supralegal de exclusão da culpabilidade, assim como Capez (2015, p.294) preconiza:

(...) Tal interpretação aflora do texto legal, pois o art.24, §2ㅇ, do CP dispõe que, quando o sacrifício não for razoável, o agente deverá responder pelo crime, tendo apenas o direito a uma redução de pena de $1 / 3$ a $2 / 3$. Ora, se a falta de razoabilidade leva tão somente á diminuição de pena, isto significa que ficou caracterizado o fato típico e ilícito e, além disto, o agente foi considerado responsável por ele (somente se aplica pena, diminuída ou não, a quem foi condenado pela prática de infração penal).

Já a teoria diferenciadora, que foi adotada pelo Código Penal Militar, disposta nos artigo 39 e 43 do referido código (BRASIL, 1969), busca a ponderação entre os valores dos bens em conflitos, sendo um critério objetivo. Dessa forma, apenas quando o valor do bem sacrificado for de cunho inferior será considerado em estado de necessidade justificante. 
Porém, conforme salienta TAVARES (2004), quando o bem destruído for de igual ou superior valor ao bem preservado, será considerada uma conduta antijurídica, também denominada estado de necessidade exculpante.

Logo, está-se diante de um exemplo estado de necessidade justificante, quando um cachorro está atacando uma criança e outra pessoa mata o animal, para salvar a vida da criança, uma vez que o bem sacrificado é de valor inferior ao bem salvo.

Assim sendo, sempre que o bem sacrificado for de valor inferior ao bem evitado, encontrar-se-á uma causa justificadora que autoriza a utilização do estado de necessidade.

E, por fim, tem-se a teoria da equidade, criada por Kant, que tenta corrigir as deficiências da lei, teoria essa que sustenta a exclusão dos atos de antijuricidade e de culpabilidade por seu estado de necessidade, onde, por razões, o agente vai deixar de ser punido.

Logo, Mirabete e Fabbrini (2016) destacam que, para que ocorra a aplicação do estado de necessidade, é necessário o preenchimento de alguns requisitos. $O$ primeiro deles é o de perigo concreto, que deve ser atual, pois há uma probabilidade de dano presente no bem jurídico, não incluindo o perigo iminente, como é usado na legitima defesa. É necessário que o agente, atue para evitar a conduta lesiva no presente momento, pois, se já ocorreu ou for futura, não haverá estado de necessidade.

Outro requisito é a proteção de direito próprio ou alheio, isto é, a proteção de qualquer bem tutelado do pátrio ordenamento, como a vida, a liberdade e a igualdade, conforme está previsto no preâmbulo da Constituição da República Federativa do Brasil (BRASIL, 1988):

Nós, representantes do povo brasileiro, reunidos em Assembleia Nacional Constituinte, para instituir um Estado Democrático, destinado a assegurar o exercício dos direitos sociais e individuais, a liberdade, a segurança, o bem-estar, o desenvolvimento, a igualdade e a justiça como valores supremos de uma sociedade fraterna, pluralista e sem preconceitos, fundada na harmonia social e comprometida, na ordem interna e internacional, com a solução pacífica das controvérsias, promulgamos, sob a proteção de Deus, a seguinte Constituição da República Federativa do Brasil.

Outro requisito indispensável é que a situação de perigo não tenha sido causada, voluntariamente, pelo agente. Há duas posições doutrinárias. Damásio (2003, p.410) evidencia:

Tem, como fundamento, um estado de perigo para certo interesse jurídico, que somente pode ser resguardado mediante a lesão de outro. Há uma colisão de bens juridicamente tutelados, causada por forças diversas, como um fato humano, fato animal, acidente ou forças naturais. Em tais casos, para proteger interesse próprio ou alheio, o Direito permite a lesão de outro bem, desde que seu sacrifício seja imprescindível para a sobrevivência daquele. Se há dois bens em perigo de lesão, o Estado permite que seja sacrificado um deles, pois, diante do caso concreto, a tutela penal não pode salvaguardar a ambos [...].

Já Toledo (1994, p. 175) sustenta:

No estado de necessidade, por inexistir a agressão ilícita, o deslinde da colisão de interesses legítimos apresenta dificuldades para cuja solução se toma necessário recorrer a outros critérios. Possuem, porém, ambos o caráter de uma agressão autorizada a bens jurídicos, com a diferença, entretanto, de que, no estado de necessidade, ocorre uma ação predominantemente agressiva com aspectos defensivos, ao passo que, na legítima defesa, se dá uma ação predominantemente defensiva com aspectos agressivos [...].

A posição majoritária também é defendida por Capez (2005, p.297): “Em que pese a conduta voluntaria, pode apresentar-se, tanto sob a forma dolosa quanto sob a culposa, entendemos que o legislador quis referir-se apenas ao agente que cria, dolosamente, a situação de perigo, excluindo, portanto, o perigo culposo[...]"

Desse modo, o perigo precisa ser atual e que não tenha sido causado, voluntariamente, pelo indivíduo. 
E, por fim a inevitabilidade por conduta diversa, ou seja, a destruição do bem jurídico deve ser evitada. Mas sempre que possível, admite o sacrifício do bem, quando não existir outra forma de salvar o bem protegido. Contudo, antes do salvamento, salienta a verificação sobre se o perigo poderia ser desviado de outro modo menos lesivo, como fuga, ou procurar uma autoridade competente, dentre outros.

\section{ESTADO DE NECESSIDADE E LEGÍTIMA DEFESA COMO CAUSAS DE EXCLUDENTE DE ILICITUDE}

As excludentes de ilicitude são causas que retiram o caráter antijurídico de uma conduta considerada criminosa. Assim, em determinadas circunstâncias onde o indivíduo pratica um fato tipificado em lei, não será considerado um criminoso, pois estará acobertado por uma excludente de ilicitude.

O próprio Código Penal Brasileiro já define o estado de necessidade e a legitima defesa, em seu artigo 23, como excludente de ilicitude, juntamente com estrito cumprimento de dever legal ou exercício regular de direito:

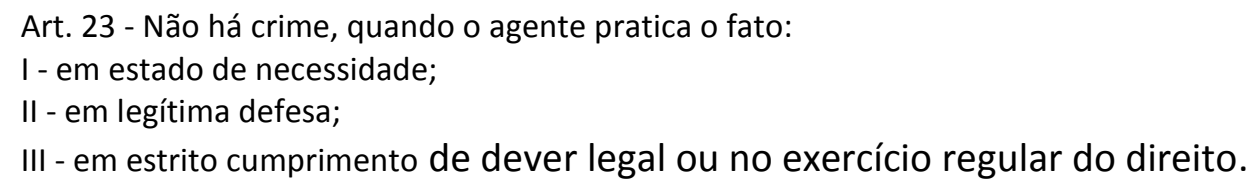

Nota-se, portanto, que o estado de necessidade é uma dessas causas que possuem o cordão de tornar lícita uma conduta ilícita, o que a torna ela uma exceção à regra. Por isto, denominada de excludente, assim como as demais mencionadas no artigo supracitado.

\section{LEGÍTIMA DEFESA}

O conceito de legítima defesa pode ser encontrado no artigo 25 do Código Penal Brasileiro (BRASIL,1940), o qual dispõe:

Art. 25. - Entende-se, em legítima defesa, quem, usando, moderadamente, dos meios necessários, repele injusta agressão, atual ou iminente, a direito seu ou de outrem.

Assim, Capez e Prado (2012, p.98), em sua obra, a definem como:

Trata-se de causa de exclusão da ilicitude que consiste em repelir injusta agressão, atual ou iminente, a direito próprio ou alheio, usando, moderadamente, dos meios necessários. Não há, aqui, uma situação de perigo pondo, em conflito, dois ou mais bens, na qual um deles deverá ser sacrificado, legitimando a repulsa.

De acordo com a definição legal e clássica, a legítima defesa ocorre, quando alguém repele agressão injusta, atual ou iminente, a direito próprio ou alheio, usando, sempre moderadamente, os meios racionais de proporção, com o elemento subjetivo, ou seja, animus defendendi. Este último é um requisito subjetivo; os demais são objetivos.

A natureza jurídica se fundamenta na necessidade que os cidadãos têm, para repelir agressão injusta em defesa de bens jurídicos, quando não há outro meio.

São duas as teorias, para explicar os fundamentos da legitima defesa: a teoria subjetiva, que considera a legítima defesa como causa excludente da culpabilidade, pois o indivíduo, em toda ação consciente e determinada a um fim, com ânimo de defesa, confere licitude ao ato de quem se defende da agressão injusta atual; já a teoria objetiva considera a legítima defesa excludente de antijuridicidade: é o fundamento em que o direito nasce com o homem e o acompanha ao longo de toda a sua vida, na colisão de bens na qual o bem de maior valor deve ser preservado. Os requisitos para a existência da legitima defesa compõem-se de agressão injusta, que seja para defesa de direito próprio ou alheio, que use, moderadamente, os meios necessários para a defesa e a inevitabilidade da conduta. (MIRABETE; FABBRINI, 2016) 
Dessa forma, Dessarte, Prado, Carvalho E. e Carvalho G. (2015) entendem como agressão toda ação violenta ou não produzida por ato humano com vistas à criação de um resultado lesivo ou que põe em perigo um direito. A ação precisa ser por ato humano, porém, quando o dono de um cachorro agressivo o instiga a pegar uma pessoa e essa vier a matar o animal, agirá, assim, em legítima defesa, pois o dono do cachorro o ordenou para a agressão.

Assim sendo, entende-se por atual a agressão presente, que se iniciou, e não está concluída. Já iminente designa agressão prestes a ocorrer. Injusta significa ilícita, mesmo que não punível. Não cabe legítima defesa em vingança.

Ao que tange o requisito de defesa de direito próprio ou alheio, o instituto o traz, para que haja uma proteção de um bem jurídico nos limites da proporcionalidade entre a ofensa e a reação, possibilitando, assim, uma resposta da vítima.

Já no uso moderado dos meios necessários, o agente deverá utilizar, moderadamente, o emprego dos meios, para repelir a agressão atual ou iminente e injusta, dentro do limite razoável, para conter a repulsa.

Logo, os meios necessários são os meios lesivos à disposição que causam dano indispensável à defesa do direito, no momento em que sofre a injusta agressão. $O$ agente poderá, até mesmo, utilizar meios desproporcionais como o utilizado no ataque, desde que esse seja o único meio colocado á disposição naquele momento.

Contudo a jurisprudência não é tão pacífica na aplicação da moderação dos meios necessários, como se pode ver no acórdão ${ }^{1}$ do Tribunal de Justiça do estado do Rio de Janeiro:

EMENTA: PENAL - LESÃO CORPORAL GRAVÍSSIMA DEFORMIDADE PERMANENTE LEGÍTIMA DEFESA - PROVA. Prevalece na doutrina penal a posição de que reconhecida a tipicidade da conduta há indício de que ela é antijurídica, desaparecendo aquela presunção quando demonstrado que o agente atuou sob a escora de qualquer das excludentes previstas no artigo 23 do Código Penal. Para afastar o reconhecimento do injusto (fato típico e ilícito), porém, não basta a simples alegação do acusado de que agira escorado na excludente de ilicitude da legítima defesa. Exige-se a prova da presença dos requisitos elencados no artigo 25 do Código Penal, o que não veio aos autos na hipótese vertente. Com efeito, o acusado desferiu violento soco no rosto de vítima idosa eis que maior de 60 anos, assim agindo porque ela estaria com um galo de propriedade do agressor, o que indica a ausência dos requisitos da moderação, sem esquecer a própria proporcionalidade, não justificando aquele comportamento bastante violento tão somente para defender patrimônio de pequeníssimo valor, sequer se tratando de animal de estimação. De ouro giro, ficando demonstrado que por força da agressão sofrida a vítima perdeu dois dentes frontais, ficando debilitada sua função mastigatória, além de ser flagrante a deformidade permanente por força do evidente dano estético, tudo devidamente reconhecido pelo laudo pericial complementar, correta a condenação pelo crime de lesão corporal gravíssima. Pena aplicada no mínimo legal com sursis pelo prazo de dois anos. Nada a prover. Apelo desprovido. (Sic)

Portanto, o indivíduo que sofre uma agressão atual, ou iminente e injusta, repele o ataque, mas, se não o faz de forma moderada, pode configurar um excesso e assim responder pelo delito.

E, por fim, inevitabilidade da agressão. Neste caso, alguns doutrinadores sustentam que também é um requisito da legítima defesa que pressupõe que o agente deve evitar, desviar-se do confronto a ele dirigido, a menos que esse seja o único meio de defesa dos seus interesses legítimos, pois somente se configurará legítima defesa, se a agressão for inevitável.

A lei brasileira não exige que se tenha que evitar a agressão commodus discessus, pois, diferentemente do estado de necessidade onde o agente obrigatoriamente tem que evitar a lesão, a legítima defesa não traz essa obrigatoriedade, de modo que o agente poderá exercitar o seu

\footnotetext{
${ }^{1}$ Apelação criminal n 0003061-62.2008.8.19.0007- DES. MARCUS BASÍLIO - Julgamento: 09/05/2011 - PRIMEIRA CÂMARA CRIMINAL- Disponível em: http://www.tjrj.jus.br/scripts/weblink.mgw. Acesso em: 22 ago. 2018
} 
direito de defesa, quando for agredido. Porém a ausência de qualquer um dos requisitos acima supramencionados exclui a legítima defesa.

Entretanto, quando o indivíduo, em uma ação inicialmente justificada, que usa os meios necessários para a repulsa, mas, no seu decorrer, intensifica, desnecessariamente, comete o excesso e responderá por tal.

Desse modo, por meio da análise feita entre os dois institutos, nota-se que as principais diferenças entre eles são que, no estado de necessidade, há uma situação de perigo, enquanto, na legítima defesa, uma agressão injusta; o estado de necessidade pode ser por comportamento humano, animal ou evento da natureza, enquanto, na legítima defesa, sempre será comportamento humano; no estado de necessidade, o perigo precisa ser atual, enquanto, na legitima defesa o perigo será atual e iminente. $E$, por fim, no estado de necessidade, a ação é defensiva, com aspectos agressivos, enquanto, na legitima defesa, a ação é agressiva, com intuito defensivo.

\section{CONCLUSÃO}

Após as análises das excludentes de ilicitude no Direito Penal brasileiro, considera-se estado de necessidade, quando existe a colisão de direitos, causada por fato humano, fato animal ou forças naturais, para proteger interesses próprios ou alheios, desde que esse ato seja imprescritível para a sua sobrevivência. E, em legítima defesa, quem repele agressão injusta, atual ou iminente, a direito próprio ou alheio, usando, sempre moderadamente, dos meios racionais de proporção.

Portanto, quando o indivíduo for atacado por um cachorro e o ataque for espontâneo e para salvar sua vida ou a de terceiros, o indivíduo matará o animal, estará, assim, coberto pelo estado de necessidade, pois não foi causado pela ação humana, configurando, dessa forma, um perigo, e não uma injusta agressão. Se o agente destruir bem de terceiros inocentes em estado de necessidade, responderá no âmbito civil.

Contudo, se o ataque for ordenado pela ação humana e o indivíduo vier a matar o animal, estará acobertado pelo instituto da legítima defesa, pois esta é aplicada apenas á agressão que advém da ação humana. Nela, o cachorro é um mero instrumento da ação humana, assim como uma arma branca ou uma arma de fogo.

É preciso ressaltar-se que, no estado de necessidade, quando possível, a fuga é obrigatória, pois o perigo deve ser inevitável. Já na legítima defesa, ainda que possível a fuga, não é imperioso, pois ninguém é obrigado a se acovardar, podendo, assim, enfrentar a agressão.

Conclui-se que o ataque de um animal irracional pode ser caracterizado como estado de necessidade ou legítima defesa, conforme supramencionado acima, o qual dependerá do reconhecimento da ação humana ou não, análise que deverá ser feita no caso concreto.

\section{REFERÊNCIAS}

ALVES, R. de O.: Legítima defesa: Aspectos Relevantes aplicados a Estados e Indivíduos. Disponível em:

<https://repositorio.ucb.br/jspui/bitstream/10869/3321/2/Rodrigo\%20De\%20Oliveira\%20Alves.p df>. Acesso em: 13 mai. 2018.

BRASIL. Tribunal de Justiça do Rio de Janeiro. Apelação criminal n 0003061-62.2008.8.19.0007DES. MARCUS BASILIO - Julgamento: 09/05/2011 - PRIMEIRA CÂMARA CRIMINAL- Disponível em: <http://www.tjrj.jus.br/scripts/weblink.mgw>. Acesso em: 22 ago. 2018

CAPEZ, F. Curso de Direito penal: Parte geral: v.1,19 ed. São Paulo: Editora Saraiva, 2015. 
CAPEZ, F.; PRADO, S. Código Penal Comentado. 3 ed. São Paulo: Editora Saraiva, 2012.

GOMES, L. F. Direito penal: Parte geral: v. 2, São Paulo: Revista dos Tribunais, 2007.

JESUS, D. Direito penal: Parte geral: v.1 - 32 ed., São Paulo: Editora Saraiva, 2011.

MIRABETE, J. F. FABBRINI, R. N.: Manual do Direto penal: Parte geral: v.1, 32 ed. São Paulo: Editora Atlas, 2016.

SOUZA, A. N.: A obrigatoriedade do estado de arcar com a defesa técnica do Policial Militar nos casos de excludente de ilicitude. Disponível em:

<https://repositorio.ufjf.br/jspui/bitstream/ufjf/6209/1/ariellyenascimentodesouza.pdf>. Acesso em: 20 mai. 2018.

TAVARES, H.G.M. Estado de necessidade como excludente de culpabilidade. Disponível:< https://jus.com.br/artigos/5959/estado-de-necessidade-como-excludente-de-culpabilidade>. Acesso em: 21 mai. 2018. 